\title{
Ultrathin Octahedral CuPt Nanocages Obtained by Facet Transformation from Rhombic Dodecahedral Core-Shell Nanocrystals
}

\begin{abstract}
Chin-Sheng Kuo, ${ }^{\dagger, \Delta}$ Lian-Ming Lyu, ${ }^{\dagger, \Delta}$ Ruo-Fang Sia, ${ }^{\dagger, \wedge}$ Hung-Min Lin, ${ }^{\dagger, \S}$ Brian T. Sneed, ${ }^{\#}$ Ching-Feng Chen, ${ }^{\dagger, \wedge}$ Joyce Chang, ${ }^{\dagger}$ Te-Wei Chiu, ${ }^{\wedge}$ Yu-Chun Chuang, ${ }^{*, \ddagger}$ and Chun-Hong Kuo ${ }^{*, \dagger}, \stackrel{ }{\perp}$
\end{abstract}

${ }^{\dagger}$ Institute of Chemistry, Academia Sinica,128, Sec 2, Academia Road, Taipei 11529, Taiwan

${ }^{\wedge}$ Department of Materials and Mineral Resources Engineering, National Taipei University of Technology, 1, Sec 3, Zhongxiao E. Rd, Taipei 10608, Taiwan

${ }^{\S}$ Department of Chemistry, National Taiwan University, 1, Sec 4, Roosevelt Rd, Taipei 10617, Taiwan

${ }^{\#}$ Cabot Microelectronics, 870, N Commons Dr, Aurora, Illinois 60504, United States ${ }^{\ddagger}$ National Synchrotron Radiation Research Center, 101, Hsin-Ann Rd, Hsinchu 30076, Taiwan ${ }^{\perp}$ Institute of Materials Science and Engineering, National Central University, 300, Zhongda Rd, Jhongli 32001, Taiwan

Corresponding Author:

*(Y.-C. Chuang) E-mail: chuang.yc@nsrrc.org.tw

*(C.-H. Kuo) E-mail: chunhong@gate.sinica.edu.tw

Number of pages: 22, Number of scheme: 1, Number of figures: 22 


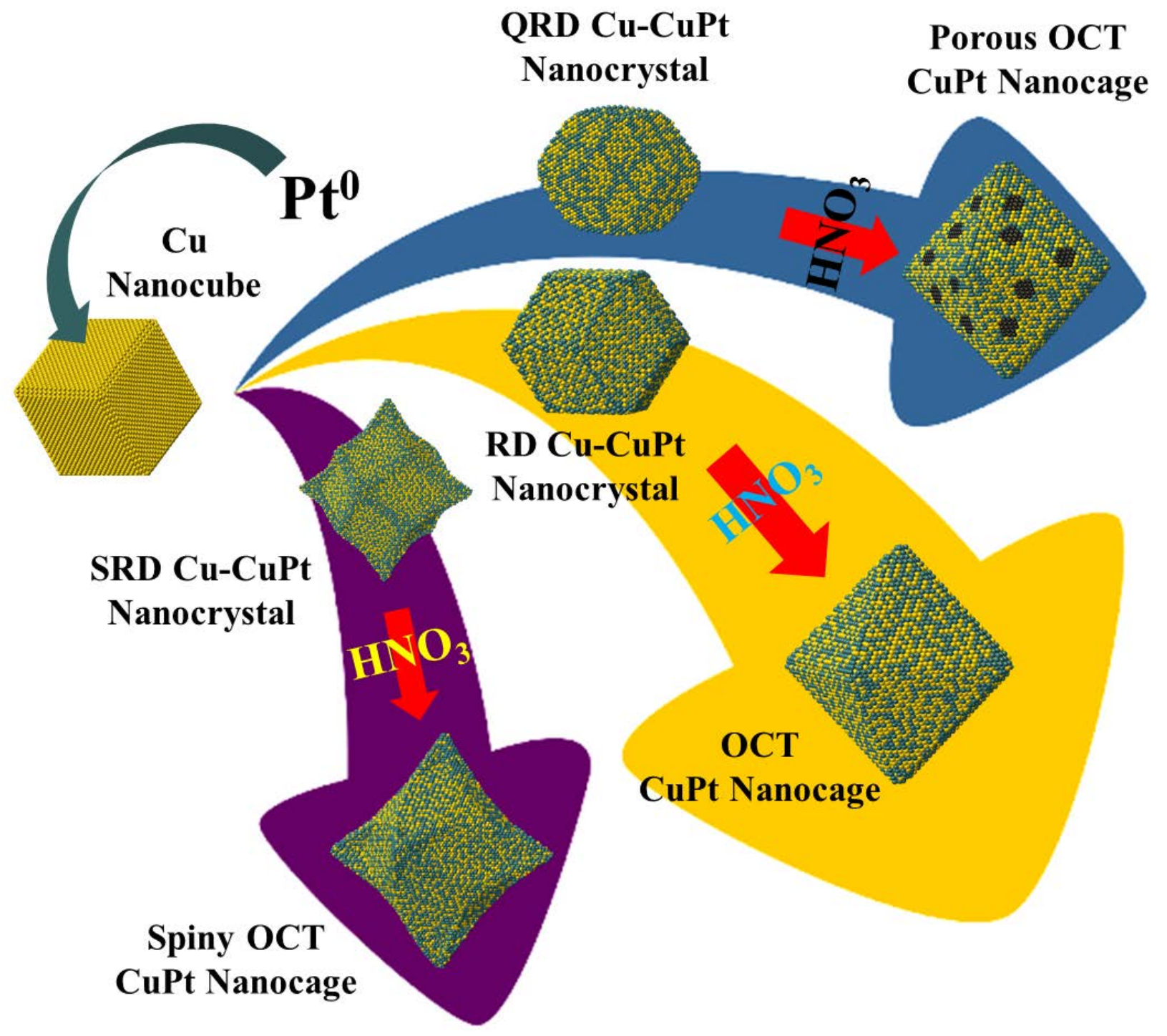

Scheme S1. Schematic illustration for the morphological transformations from a Cu nanocube to different types of CuPt nanocages. 

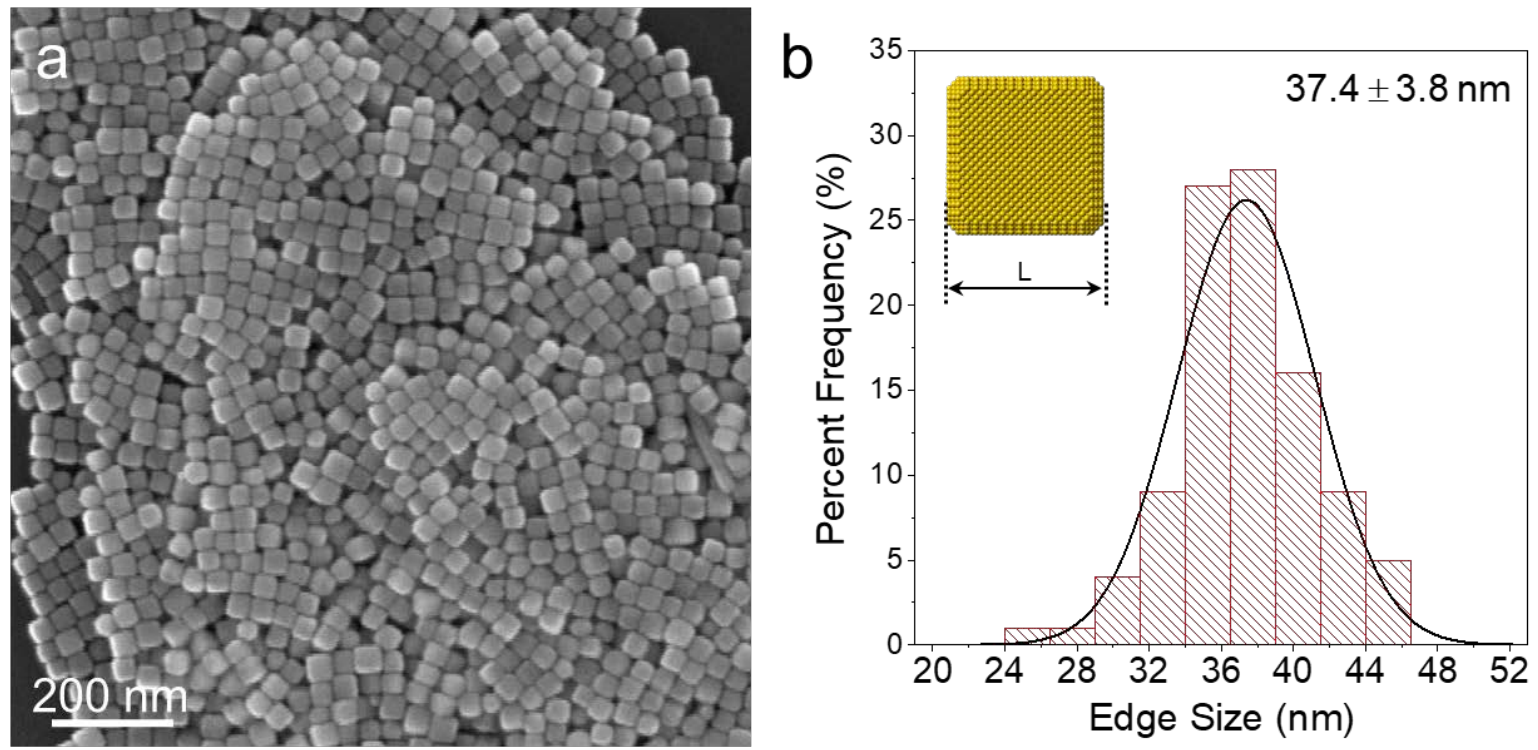

Figure S1. (a) SEM image of $\mathrm{Cu}$ nanocubes used as the templates for $\mathrm{Pt}$ coating. (b)

Size-distribution histogram of the cube-edge sizes.
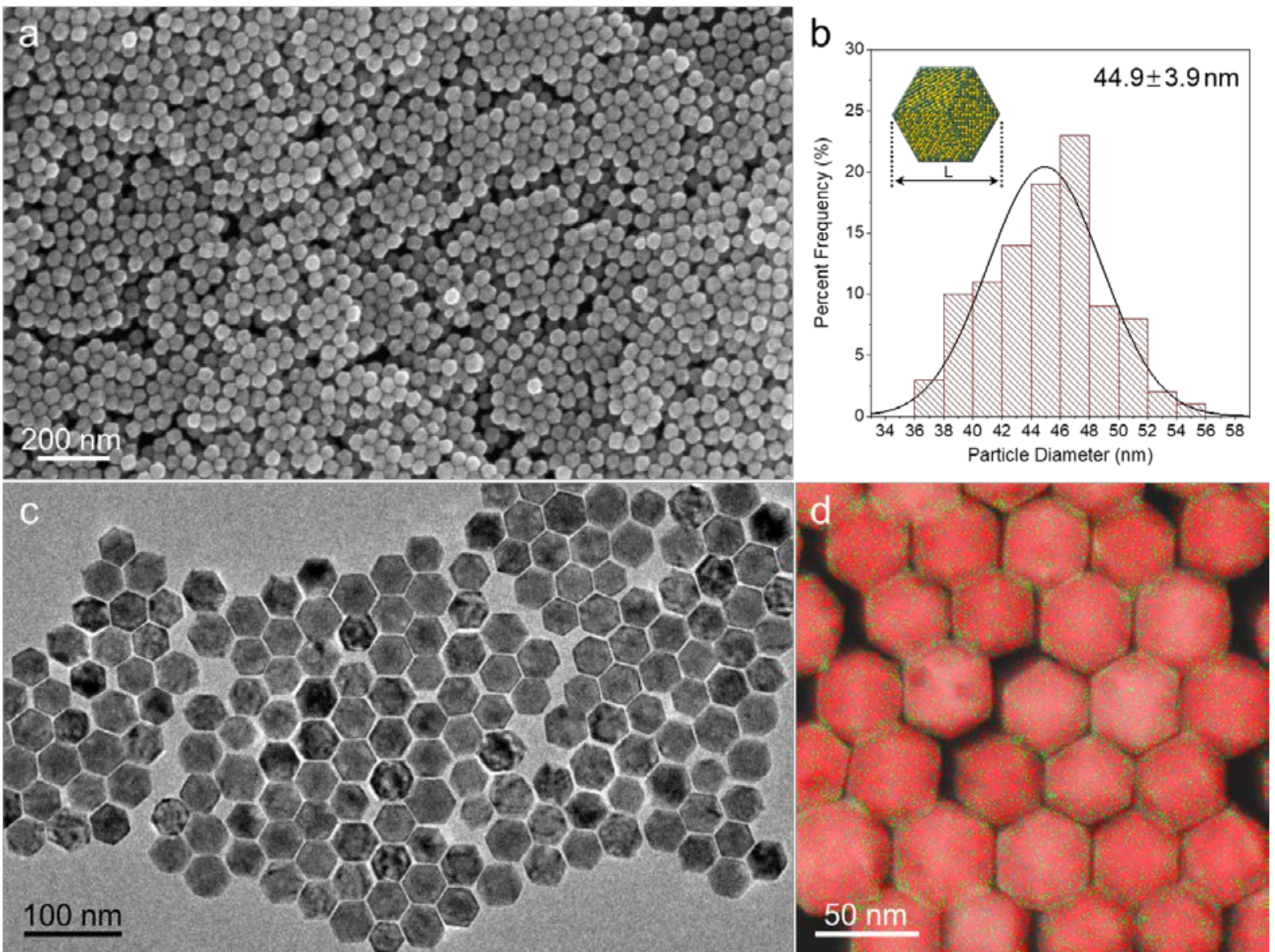

Figure S2. Low-magnification (a) SEM image, (b) size-distribution histogram, (c) bright-field TEM image, and (d) EDS map of RD Cu-CuPt core-shell nanocrystals. 


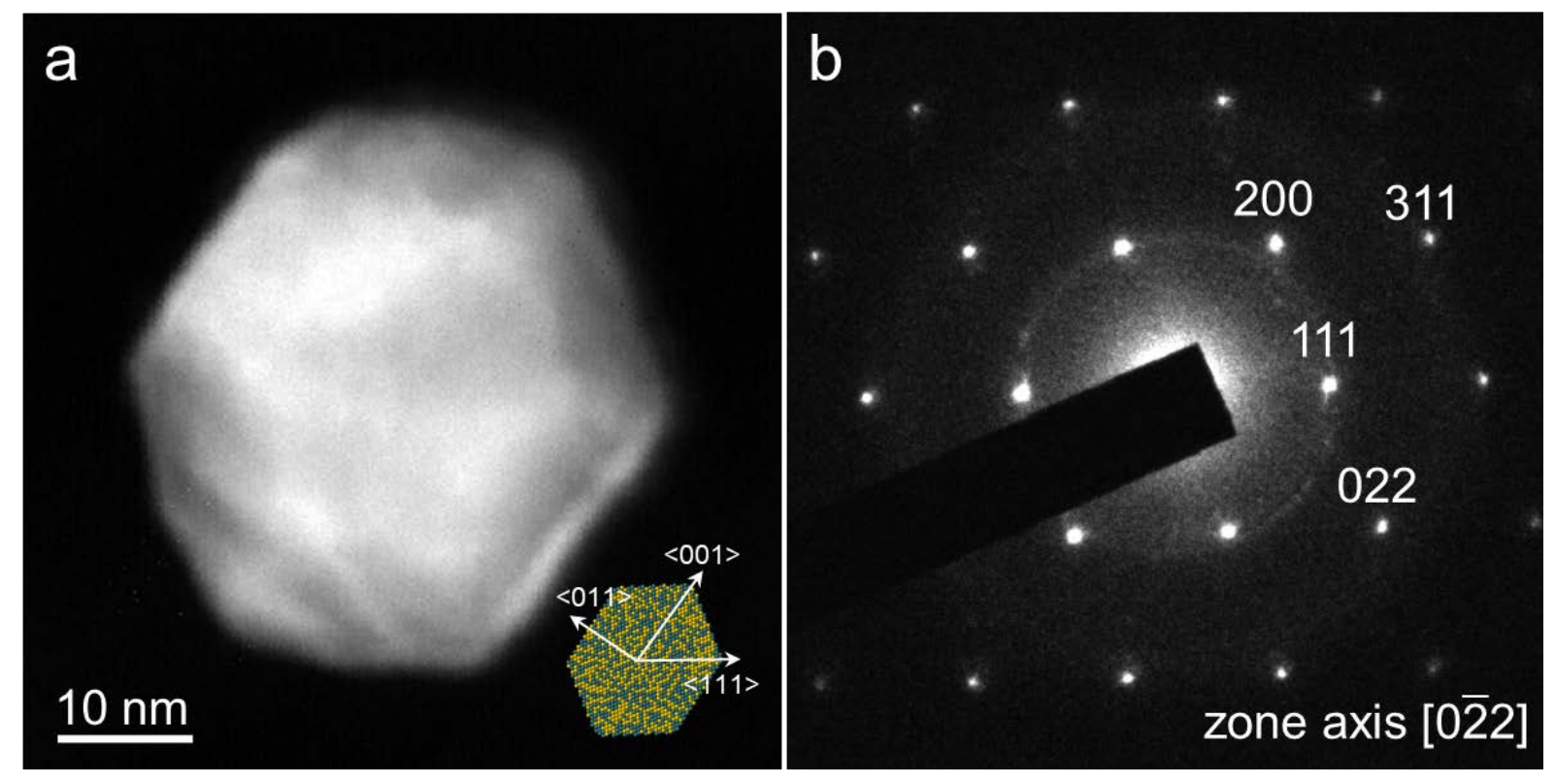

Figure S3. (a) HAADF-STEM image of a single RD Cu-CuPt core-shell nanocrystal, and (b) its corresponding SAED pattern recorded along the zone axis [0 $\overline{2} 2]$. 


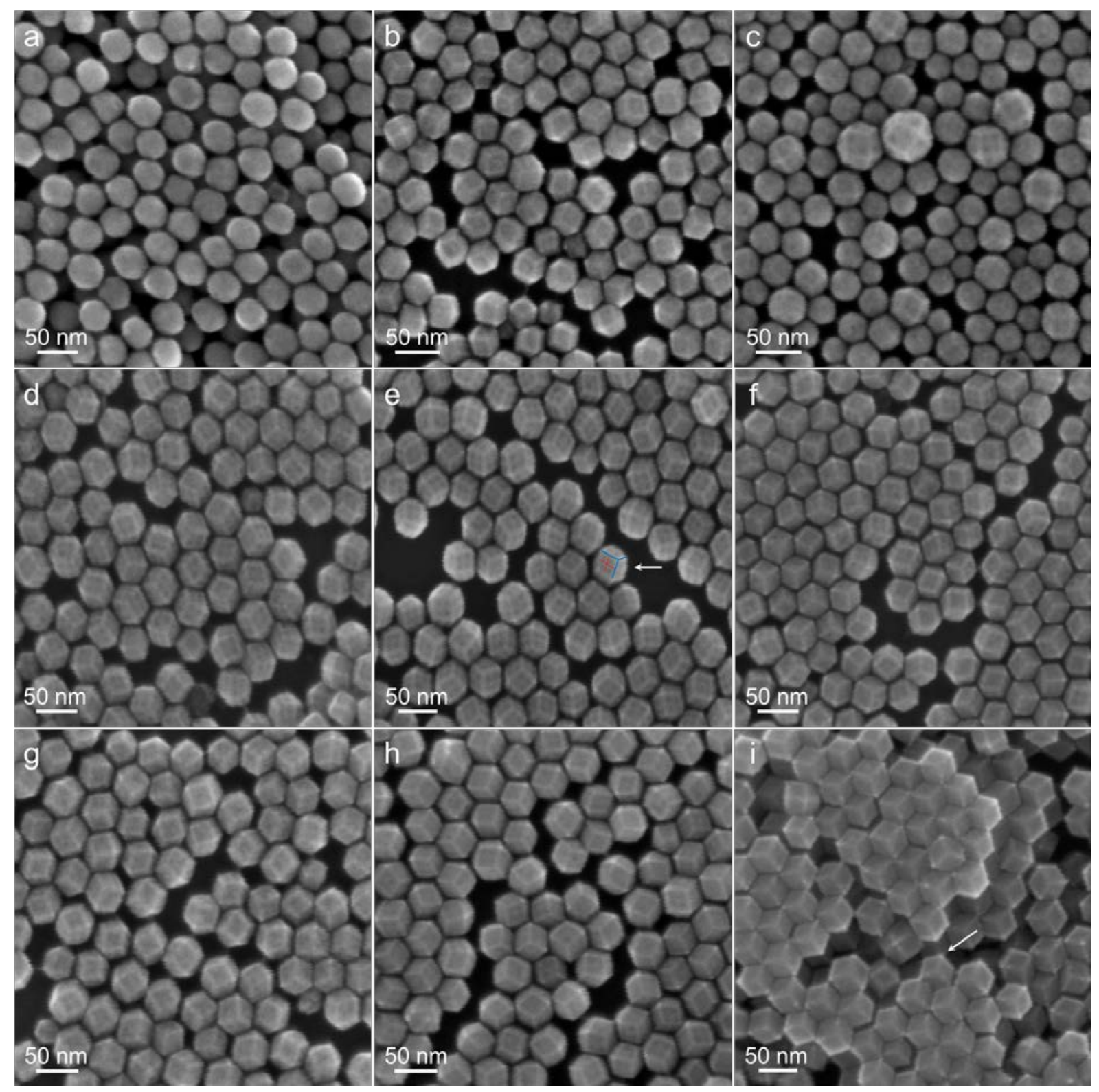

Figure S4. SEM images of Cu-CuPt core-shell intermediates obtained at different reaction times of

(a) 1, (b) 5, (c) 10, (d) 20, (e) 30, (f) 40, (g) 50, (h) 90, and (i) 120 minutes. 

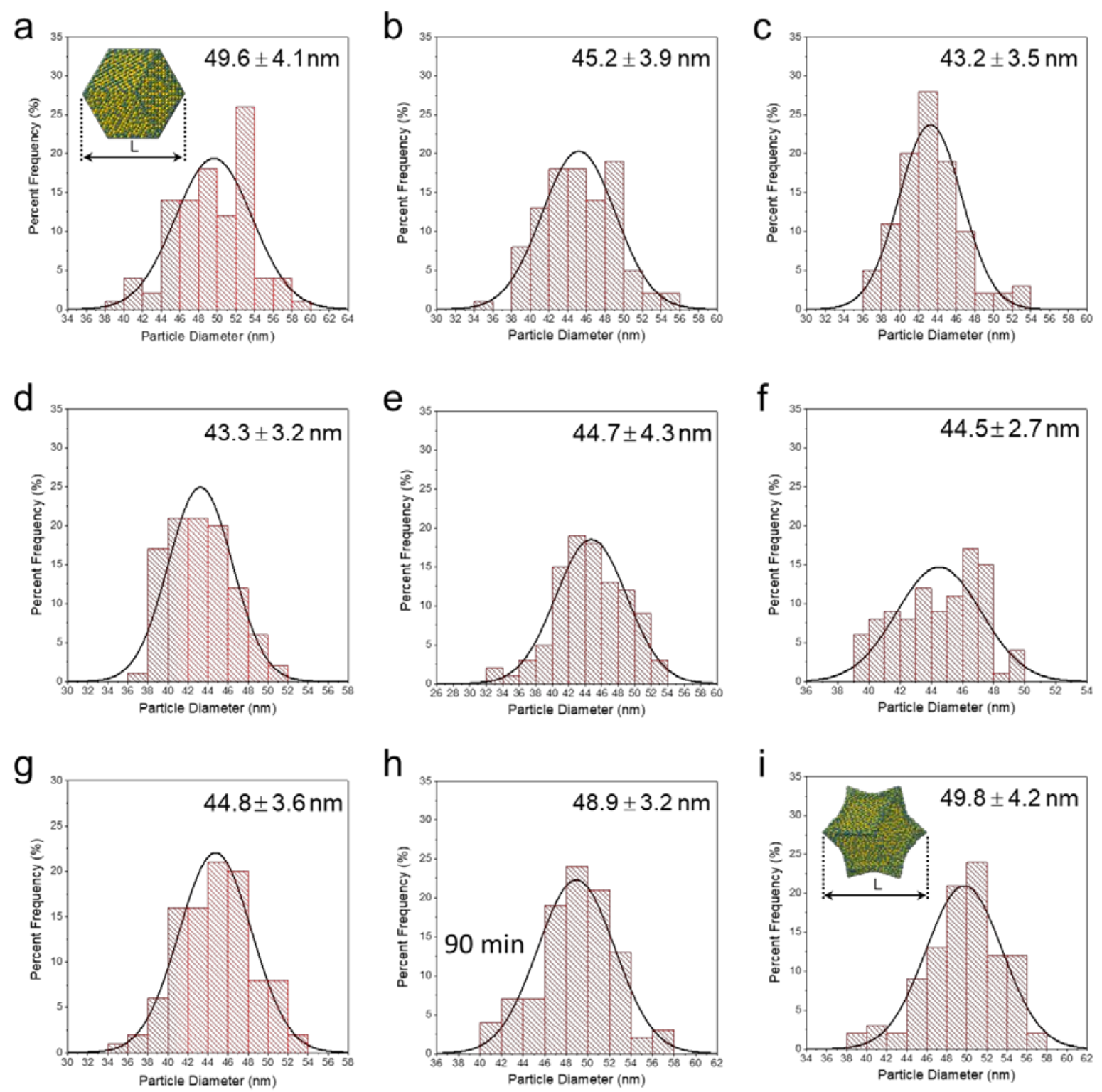

Figure S5. Size-distribution histograms of Cu-CuPt core-shell intermediates obtained at different reaction times of (a) 1, (b) 5, (c) 10, (d) 20, (e) 30, (f) 40, (g) 50, (h) 90, and (i) 120 minutes. 

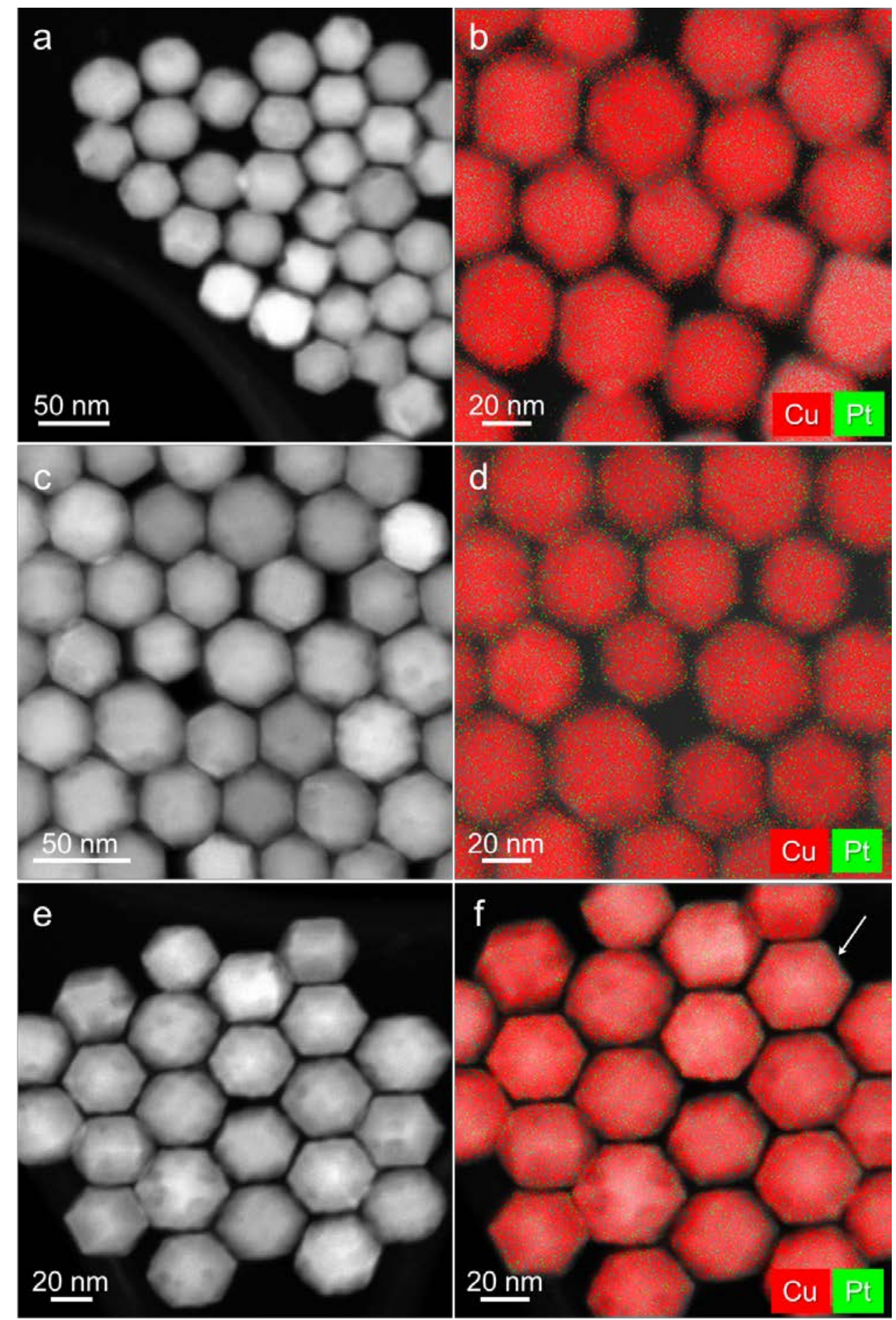

Figure S6. HAADF-STEM images and EDS maps of Cu-CuPt core-shell nanocrystals obtained at the reaction times of (a, b) 1, (c, d) 5, and (e, f) 10 minutes. 


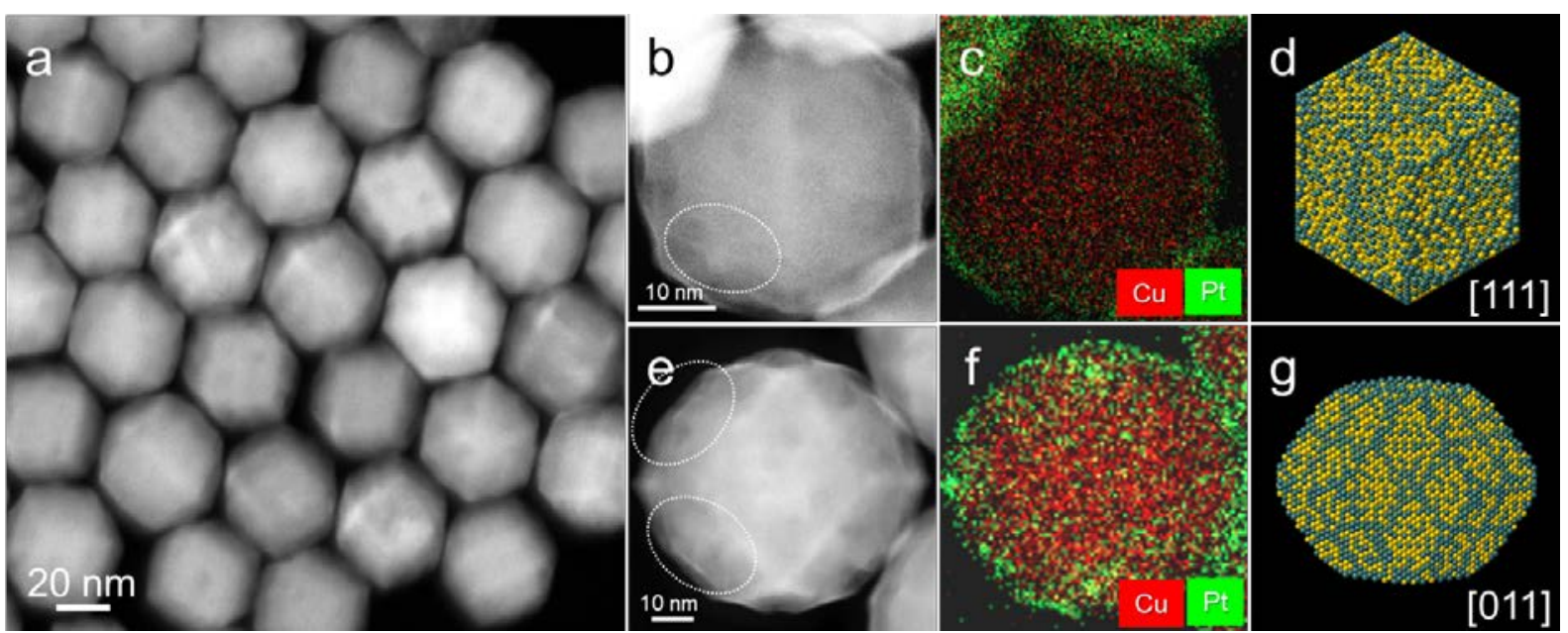

Figure S7. (a) HAADF-STEM image of quasi-RD Cu-CuPt core-shell nanocrystals. HAADF-STEM images, EDS maps, and responding models of a single quasi-RD nanocrystal viewed along (b-d) [111], and (e-g) [011] directions. 

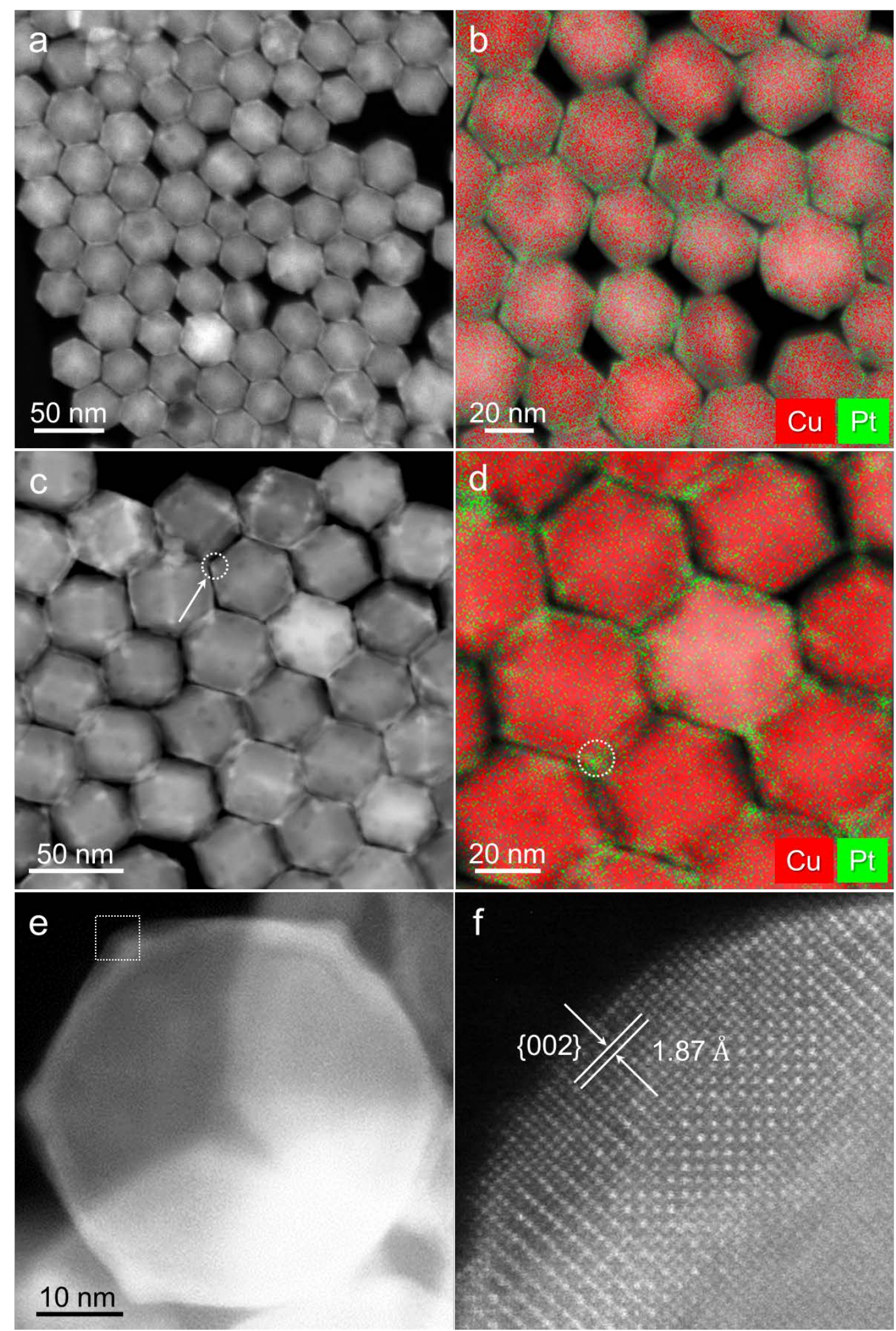

Figure S8. HAADF-STEM image and EDS map of SRD Cu-CuPt core-shell nanocrystals obtained at the reaction time of (a, b) 90 and (c, d) 120 minutes. (e) Zoom-in HAADF-STEM image and of a single SRD nanocrystal. (f) Atom-resolved HAADF-STEM imaging at one corner of the SRD nanocrystal in (e) (the square area). 


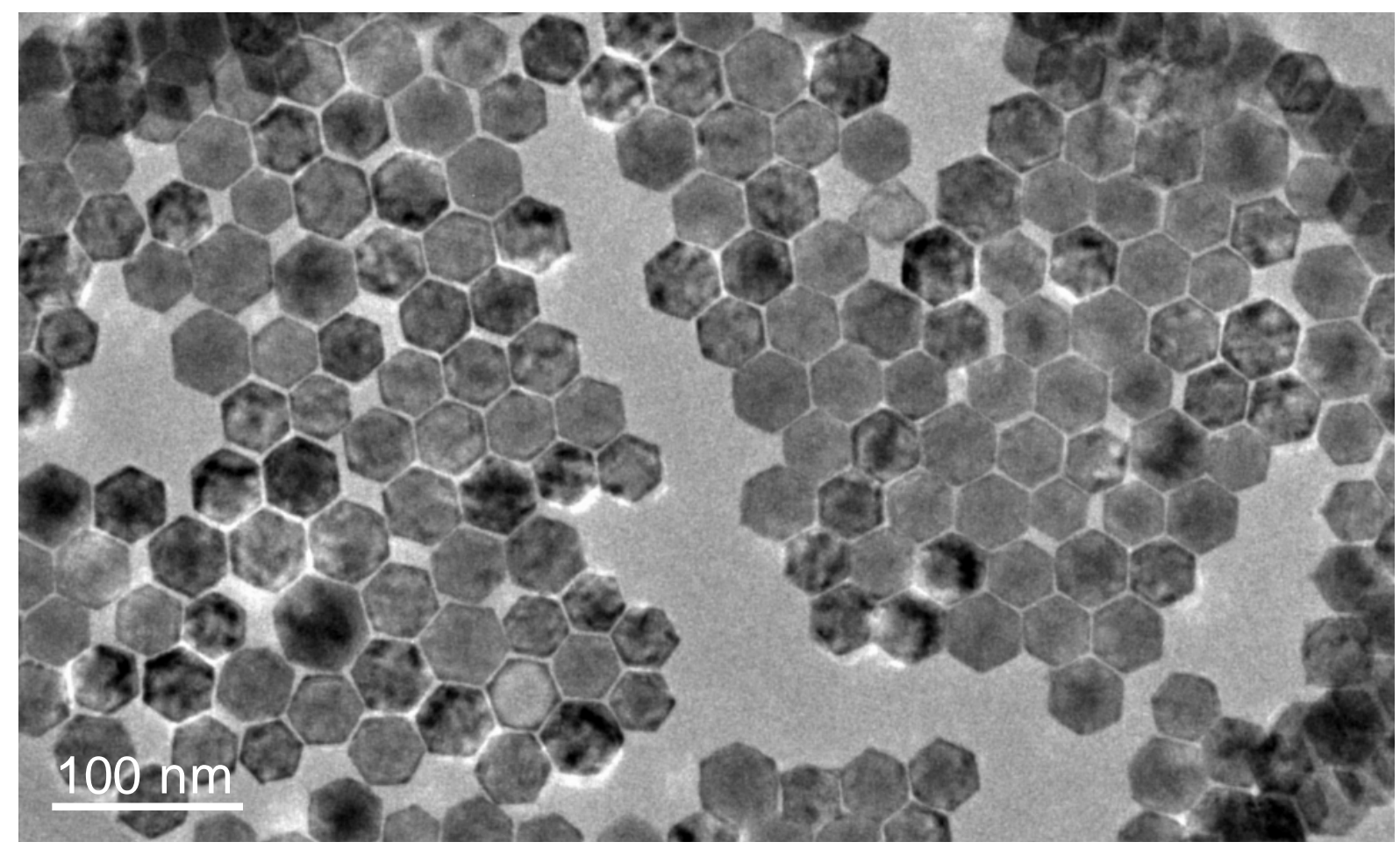

Figure S9. Low-magnification bright-field TEM image of spiny RD Cu-CuPt core-shell nanocrystals obtained at the reaction time of 120 minutes. 


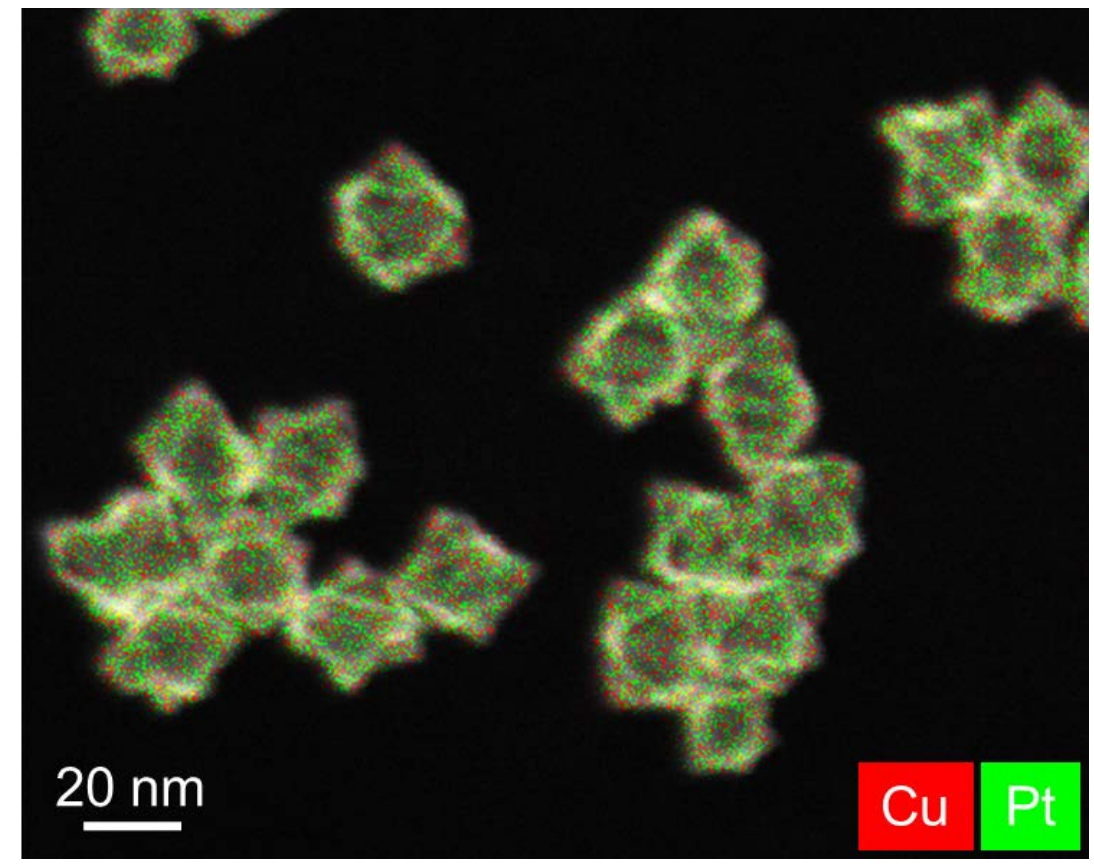

Figure S10. EDS map of octahedral CuPt nanocages.

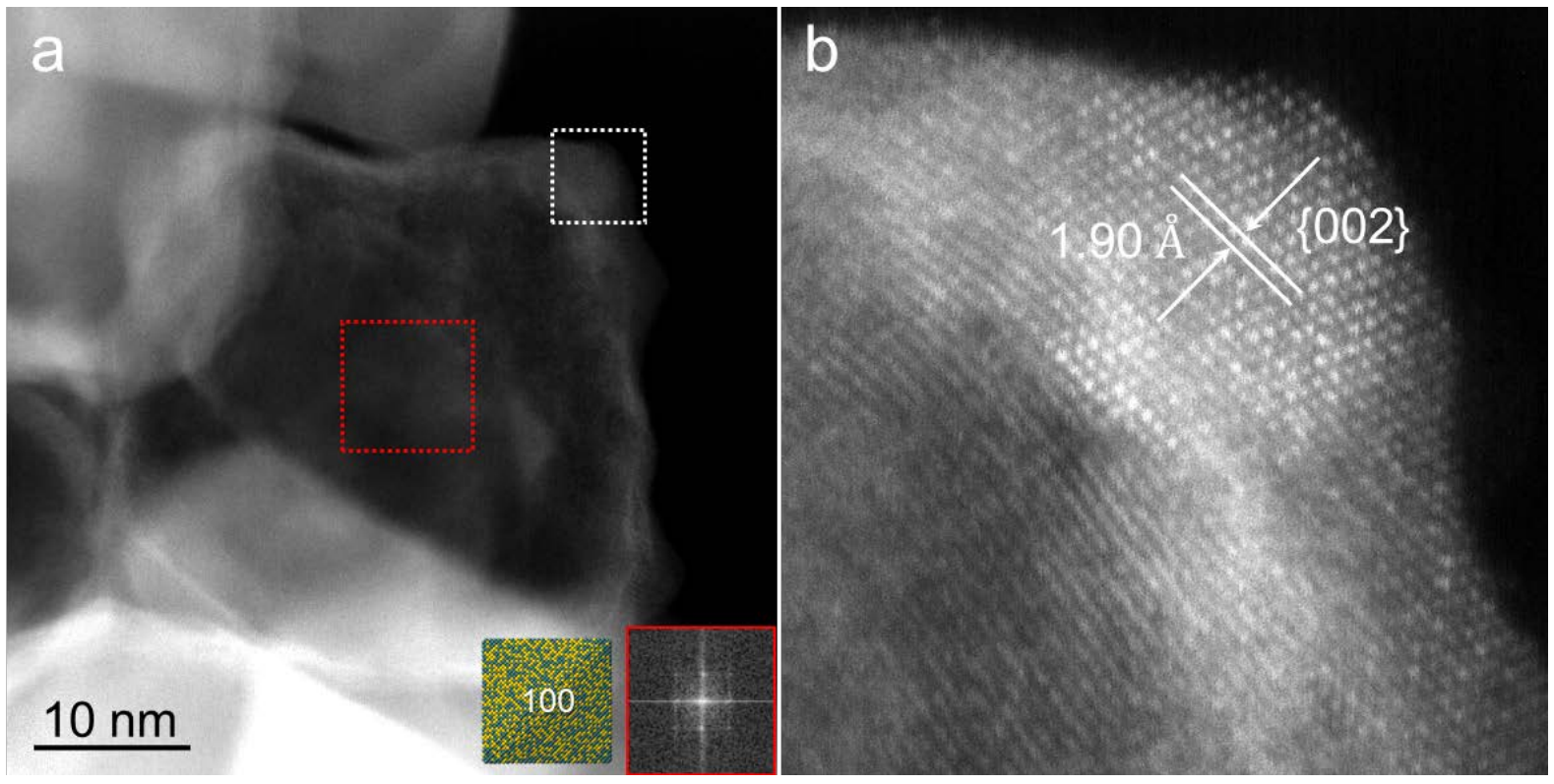

Figure S11. (a) HAADFSTEM image of a single OCT nanocage obtained at the reaction time of 60 min, and its (b) atom-resolved image of a selected corner of the nanocage in (a). The inset panel in (a) is the FFT pattern taken from the red-dash area, indicating the view direction is along $<100>$. 


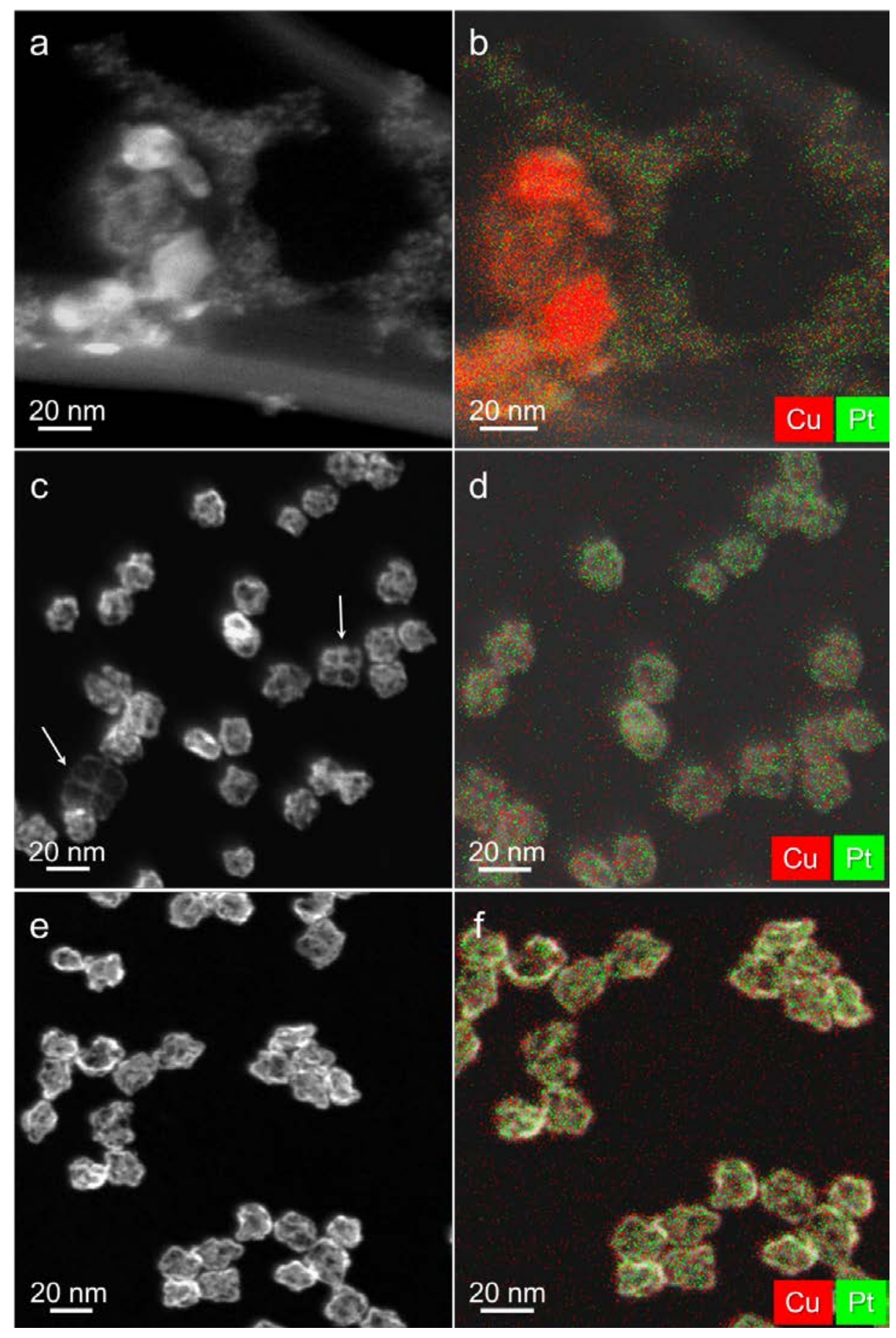

Figure S12. HAADF-STEM images and EDS maps of CuPt nanocages prepared from $\mathrm{Cu}-\mathrm{CuPt}$ core-shell nanocrystals obtained at the reaction times of (a, b) 1, (c, d) 5, and (e, f) 10 minutes. 

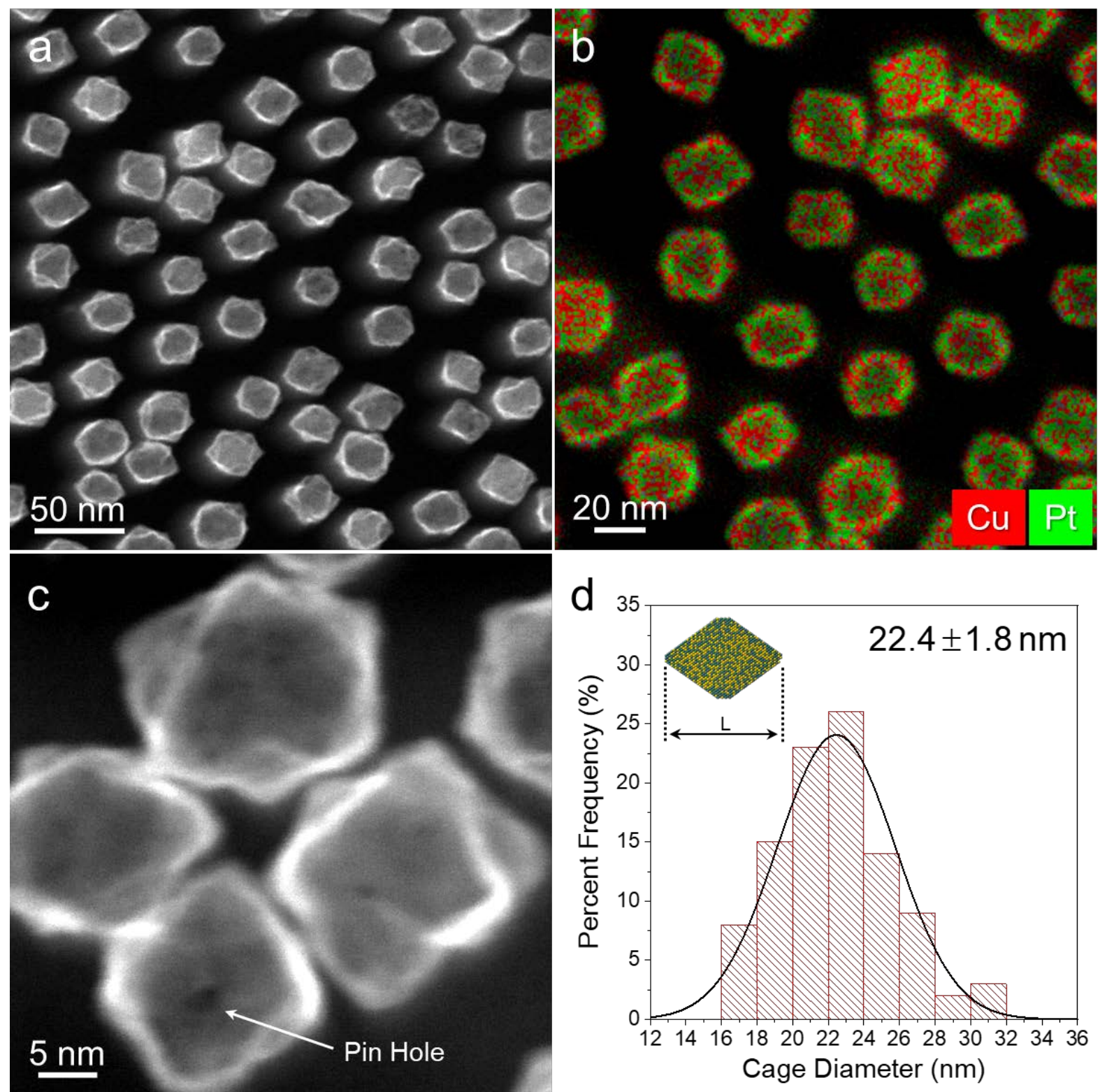

Figure S13. (a) HAADF-STEM image of OCT CuPt nanocages obtained from acid-treated quasi-RD Cu-CuPt core-shell nanocrystals. (b) EDS map of porous OCT CuPt nanocages. (c) Magnified HAADF-STEM image of several OCT nanocages showing pin holes on the surfaces. (d) The histogram of their size distribution. 

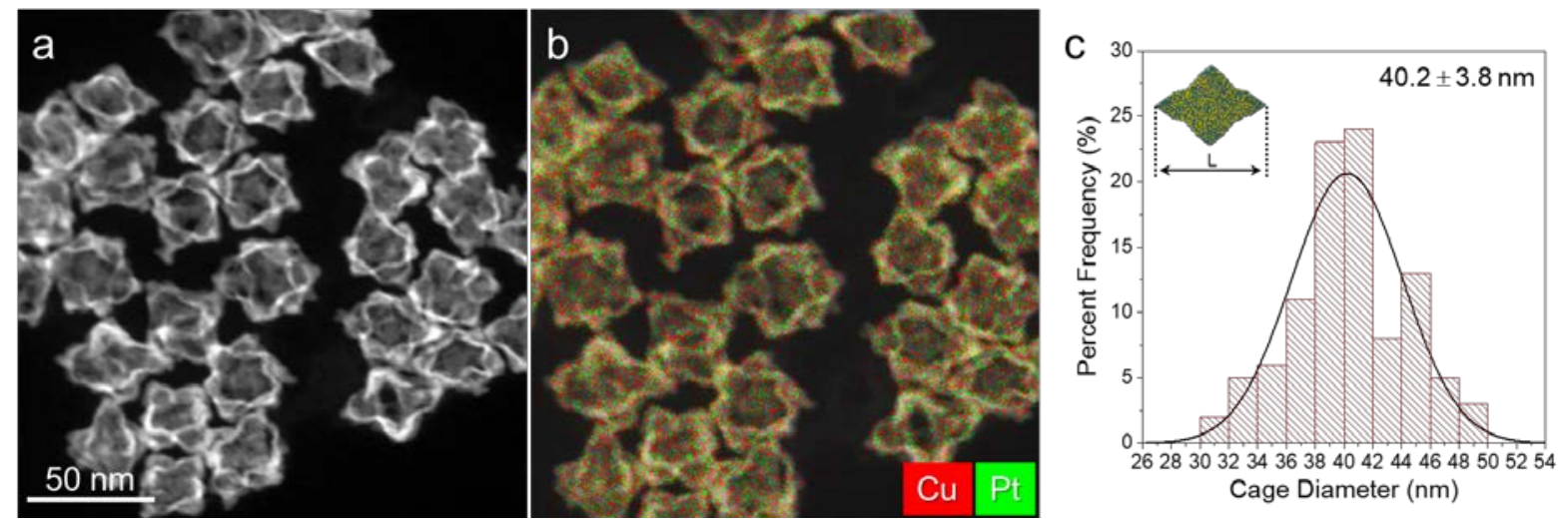

Figure S14. (a) HAADF-STEM image, (b) EDS map, and (c) histogram of size distribution for SOCT CuPt nanocages obtained at the reaction time of $120 \mathrm{~min}$. 


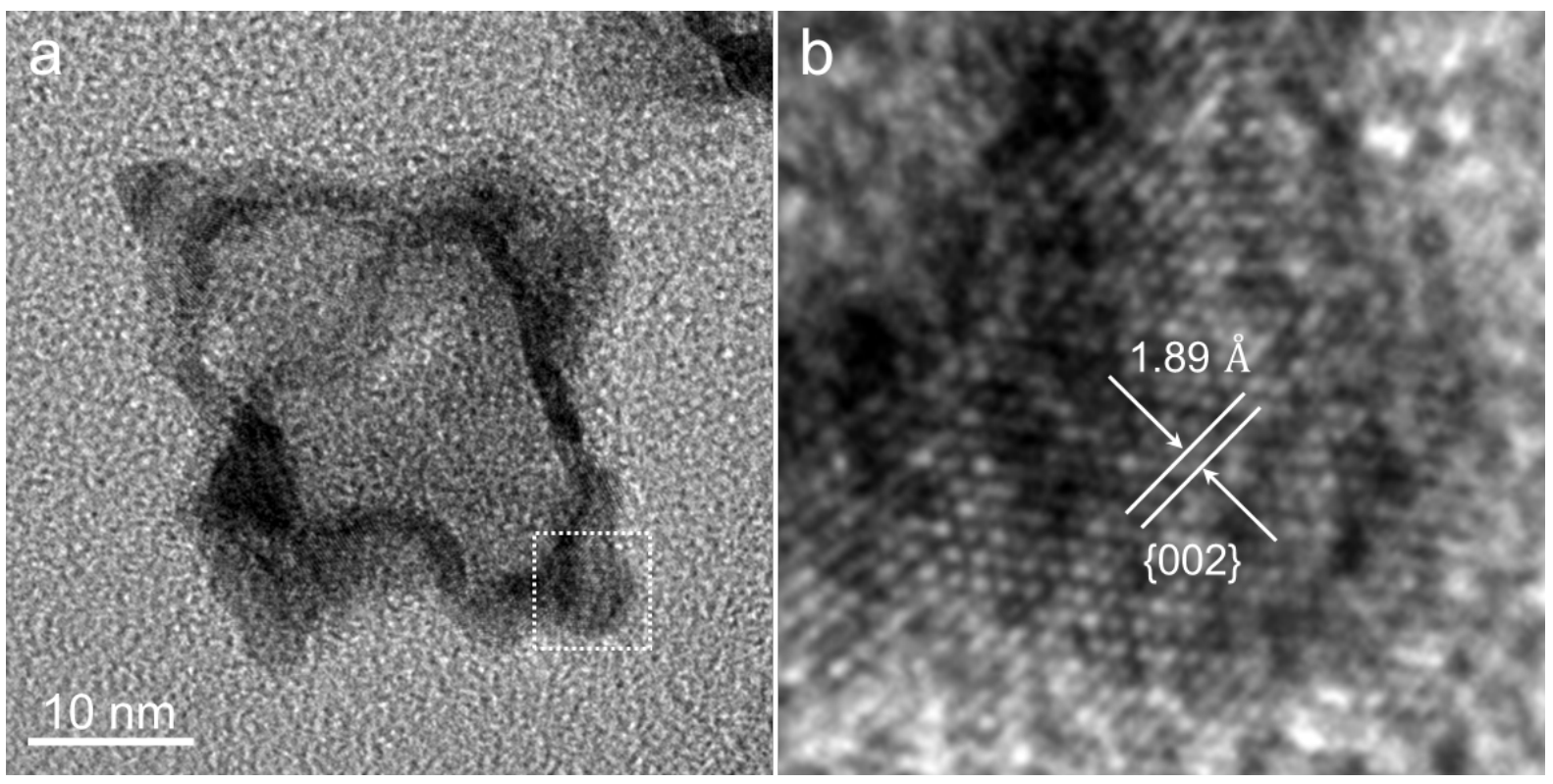

Figure S15. (a) Bright-field TEM image of a single SOCT nanocage obtained at the reaction time of 120 min. (b) HRTEM image of a selected corner of the nanocage in (a). 

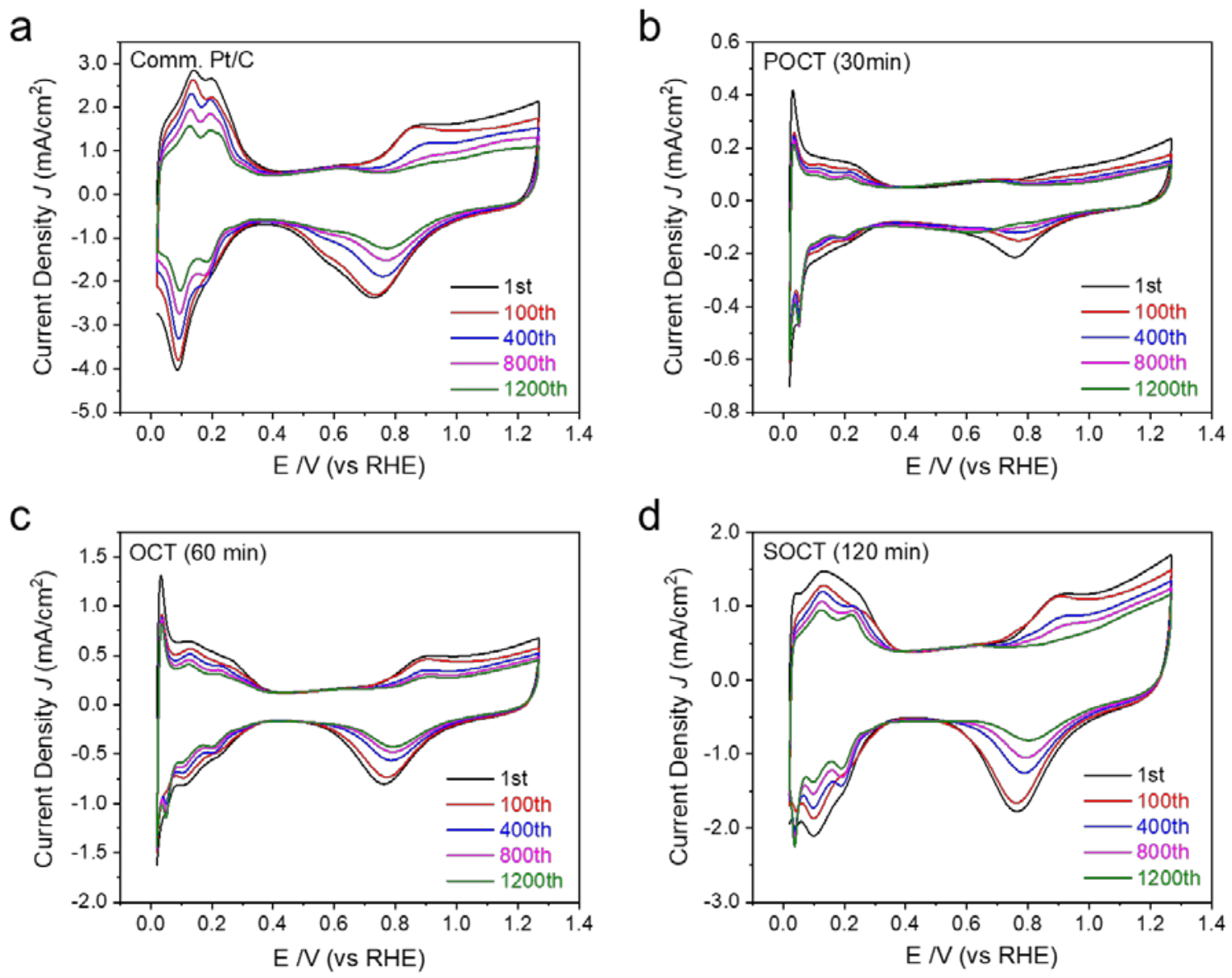

Figure S16. CVs of (a) commercial Pt/C, b) porous OCT, (c) OCT, and (d) spiny OCT CuPt nanocages before and after ADT for 1200 cycles at a sweep rate of $100 \mathrm{mV} / \mathrm{s}$ in a $0.1 \mathrm{M} \mathrm{HClO}_{4}$ solution. 
a

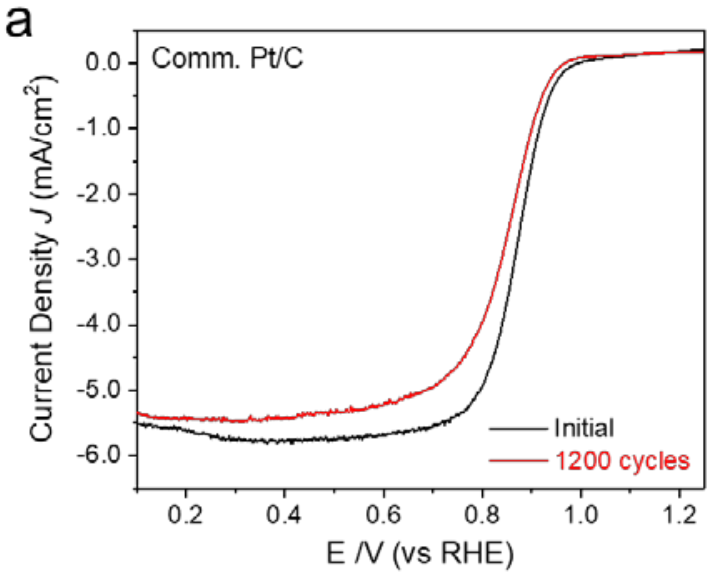

C

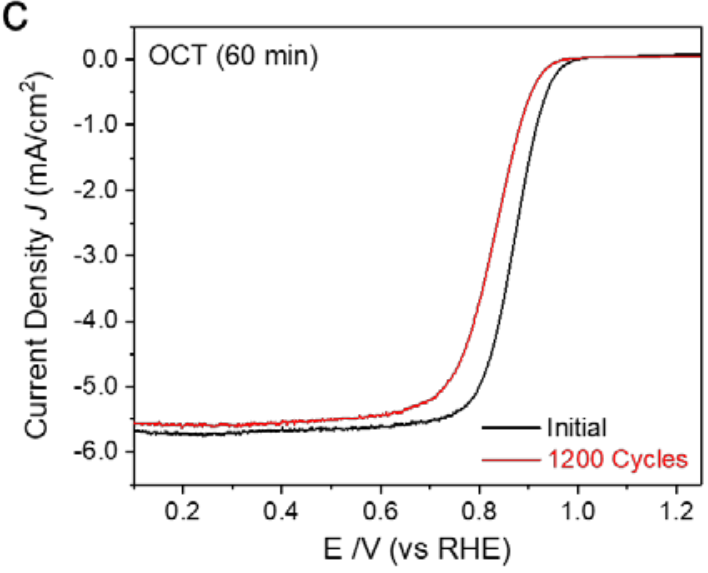

b

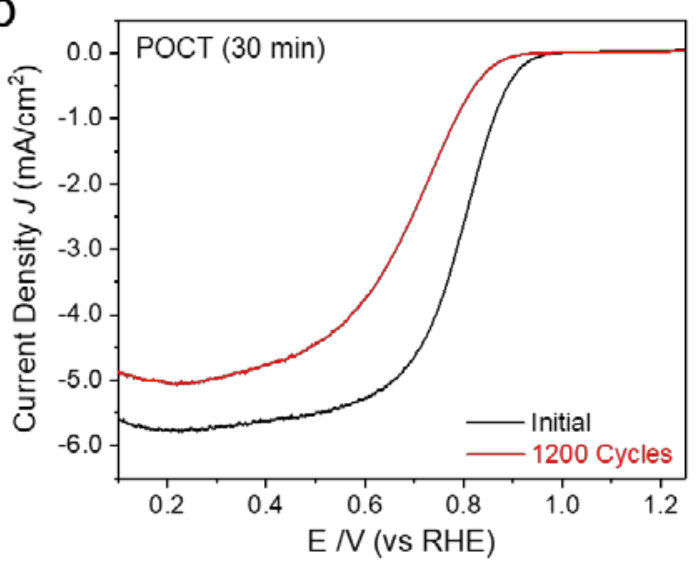

d

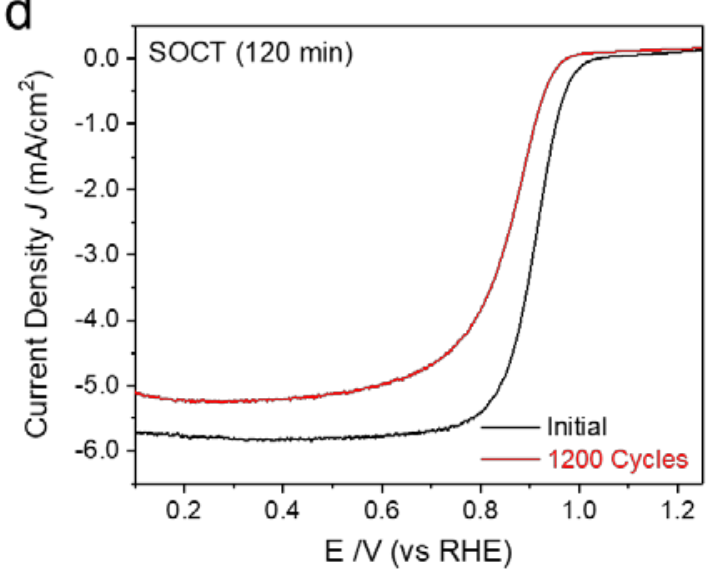

Figure S17. ORR polarization curves obtained with the catalysts of (a) commercial Pt/C, b) porous OCT, (c) OCT, and (d) spiny OCT CuPt nanocages before (black) and after (red) ADT treatments. 

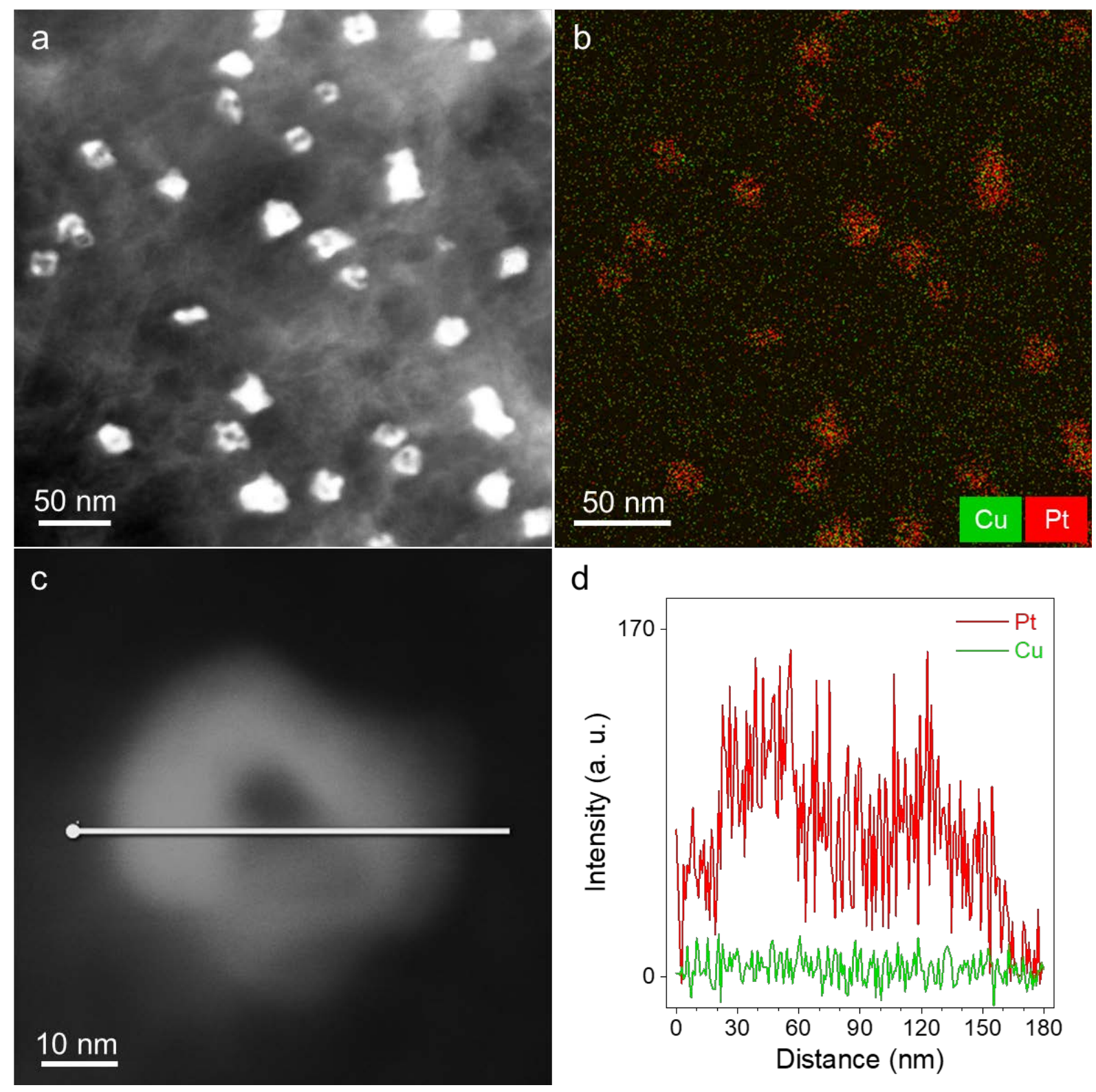

Figure S18. (a) HAADF-STEM image, (b) EDS-mapping, and (c, d) EDS-Line Scan profile of porous OCT nanocages after ADT test for 1200 cycles. 


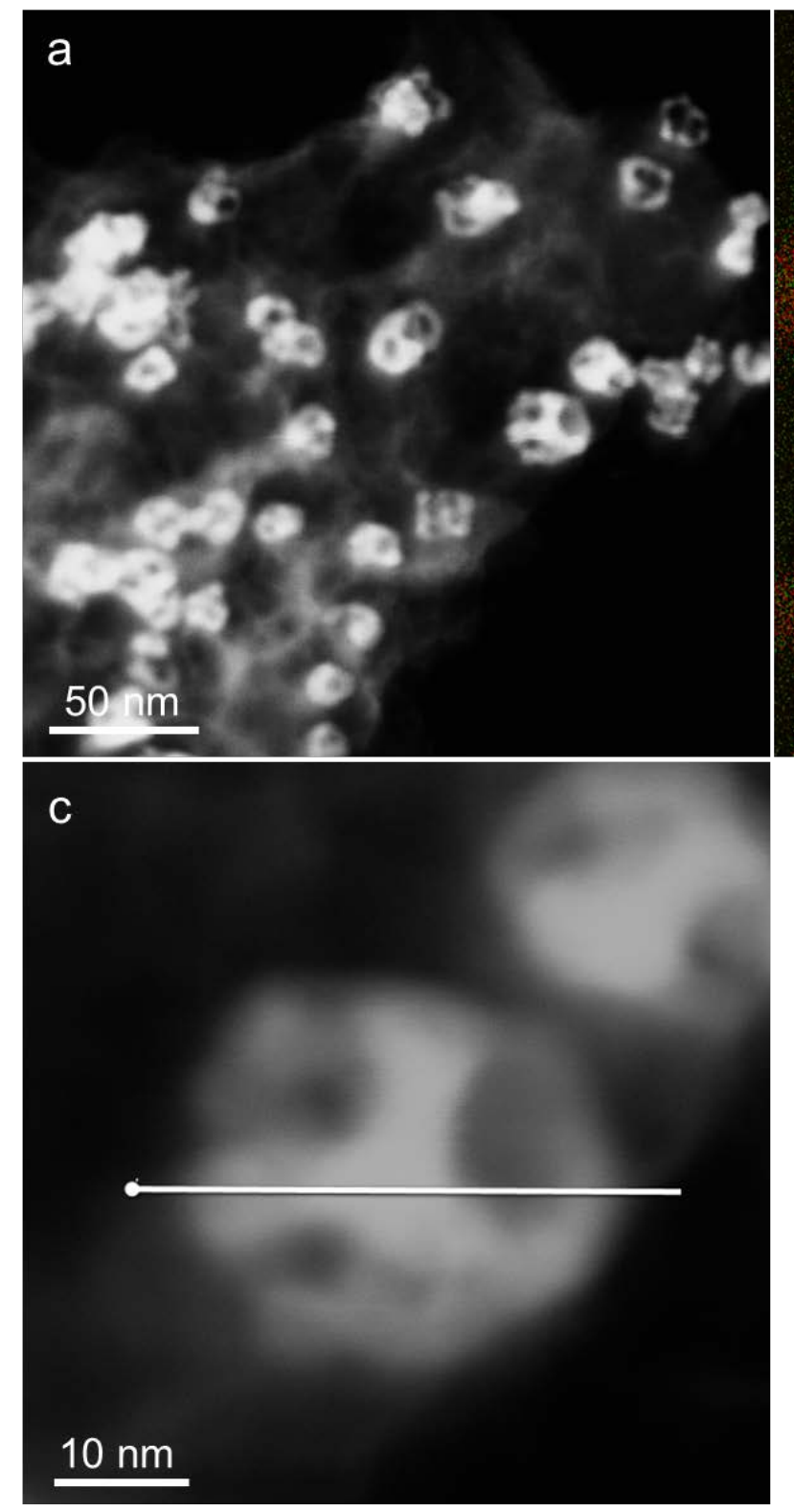

b

\section{$50 \mathrm{~nm}$}

d

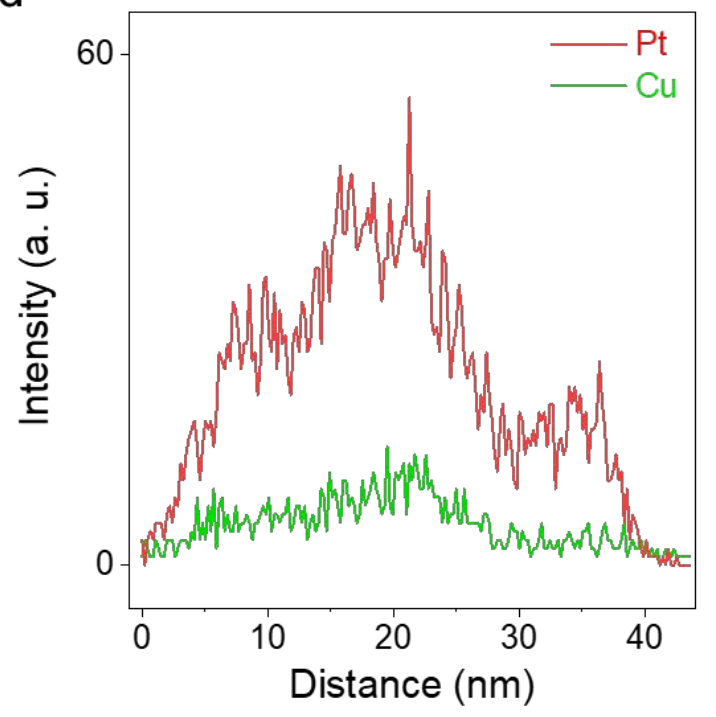

Figure S19. (a) HAADF-STEM image, (b) EDS-mapping, and (c, d) EDS-Line Scan profile of regular OCT nanocages after ADT test for 1200 cycles. 

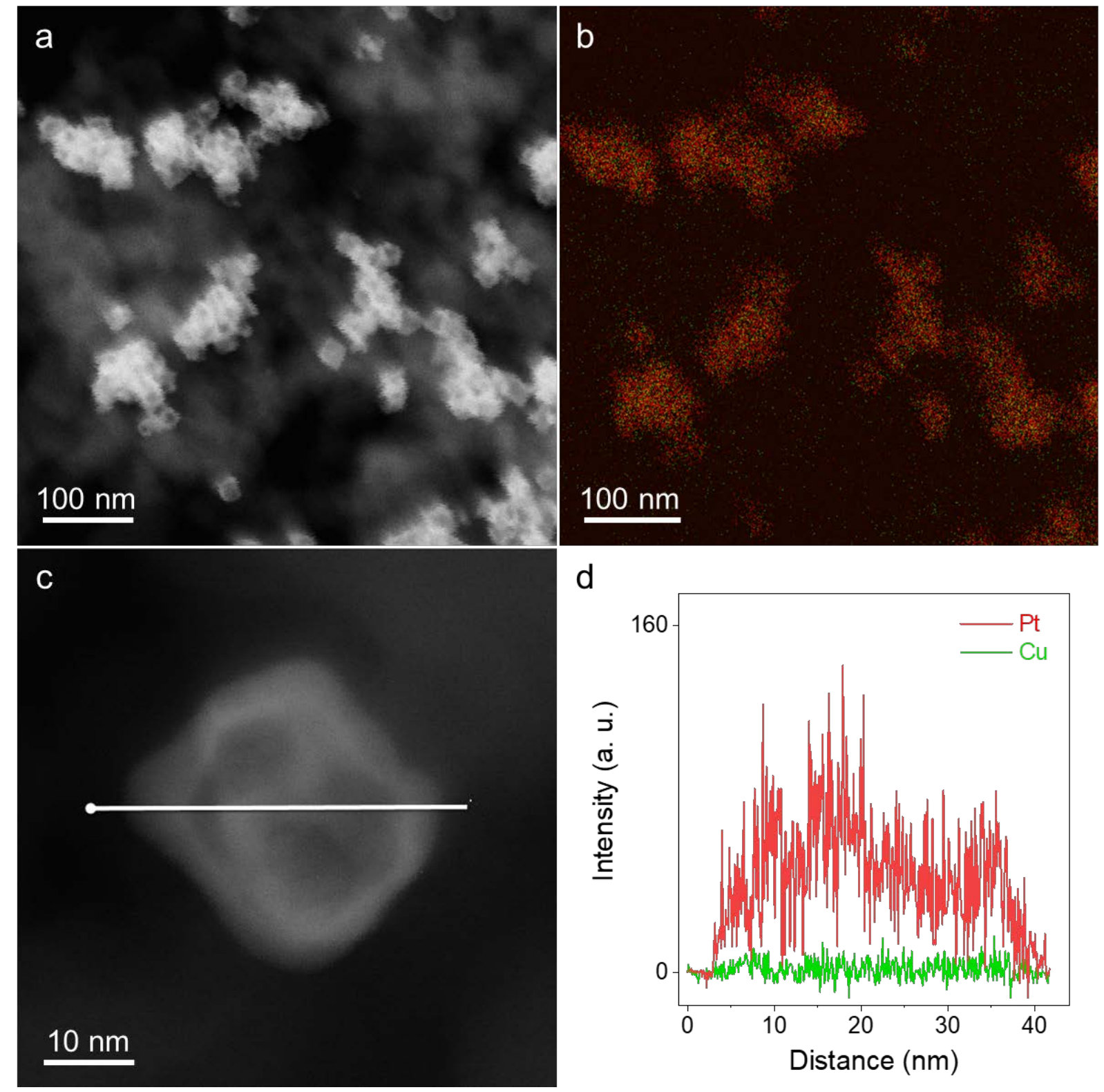

Figure S20. (a) HAADF-STEM image, (b) EDS-mapping, and (c, d) EDS-Line Scan profile of spiny OCT nanocages after ADT test for 1200 cycles. 
a

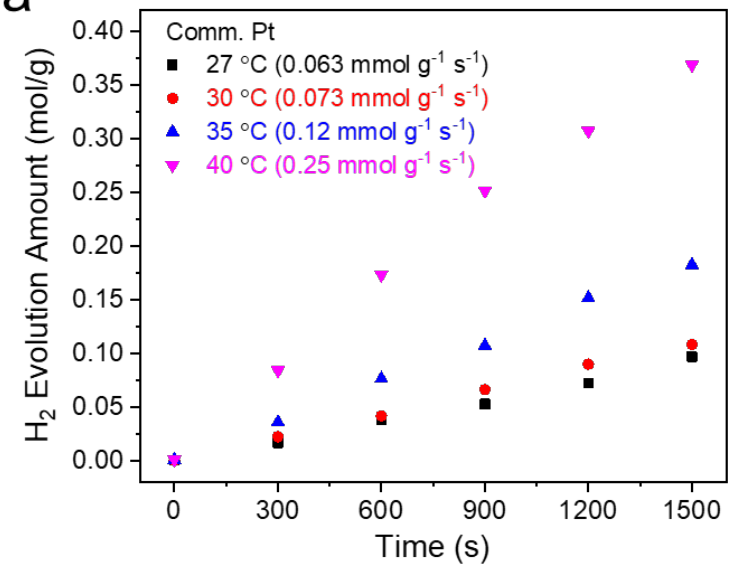

C

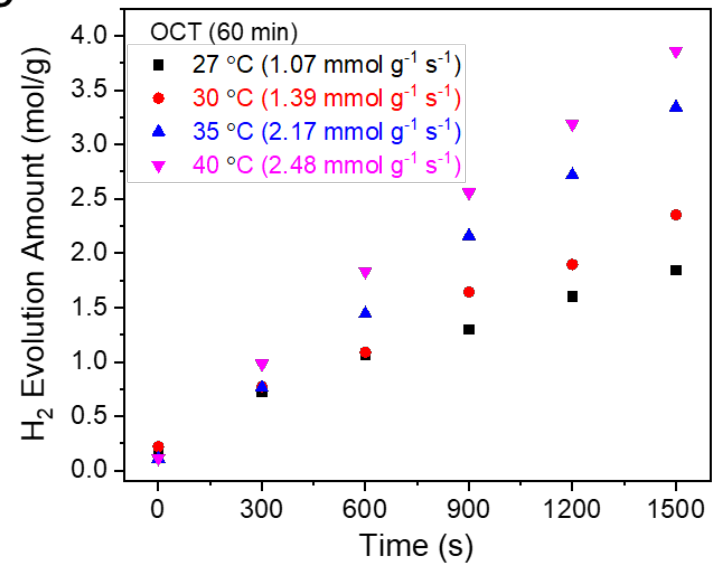

b

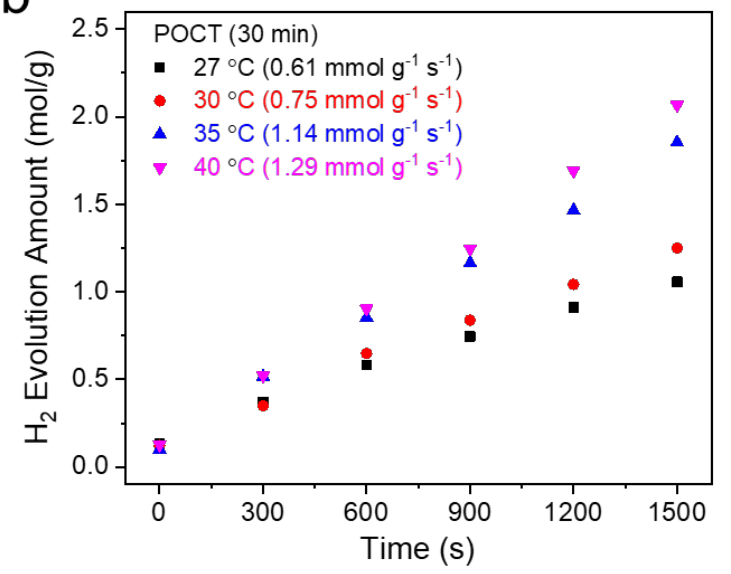

d

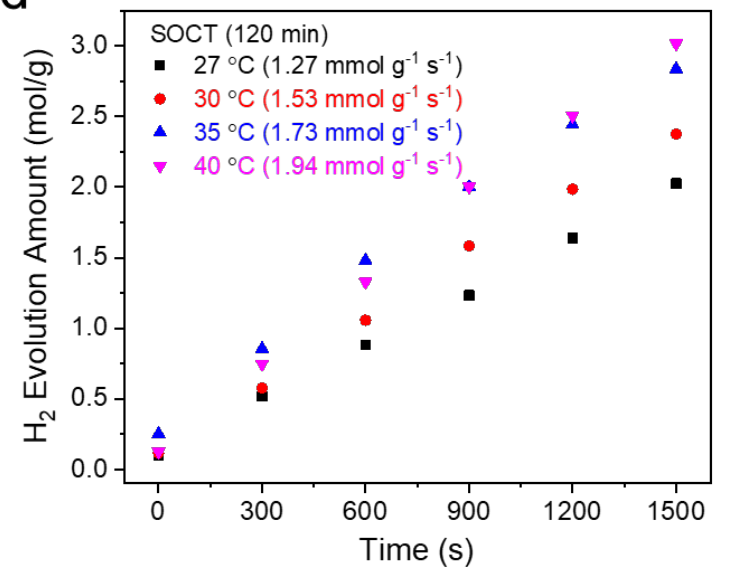

Figure S21. Time-dependent plots of $\mathrm{H}_{2}$ evolution from hydrolysis of $\mathrm{NH}_{3} \mathrm{BH}_{3}$ with the catalysts of (a) commercial Pt, b) POCT, (c) OCT, and (d) SOCT CuPt nanocages at 27, 30, 35, and $40^{\circ} \mathrm{C}$. 
a

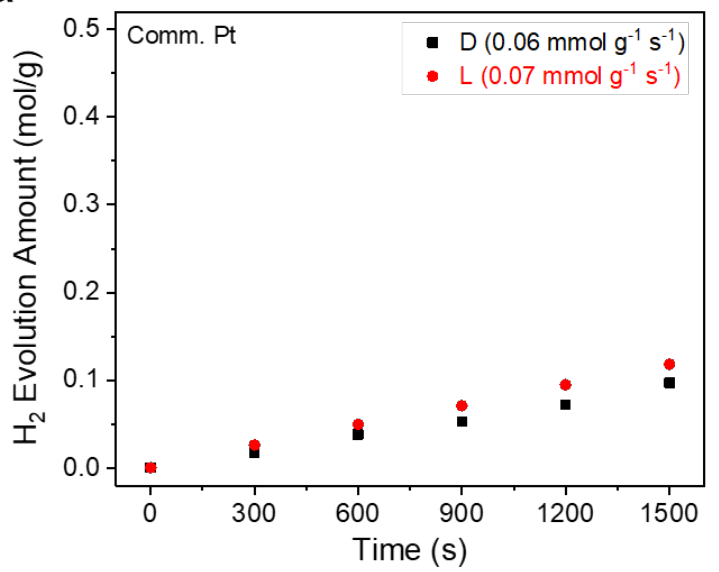

C

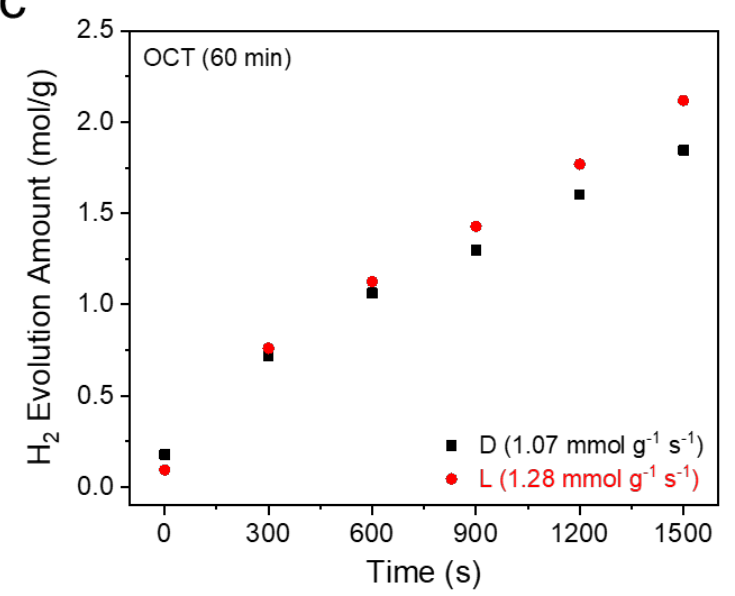

$\mathrm{b}$

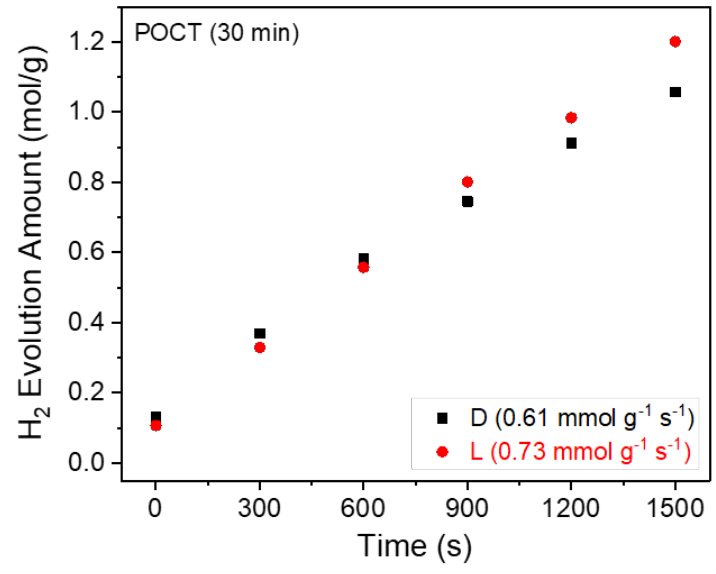

d

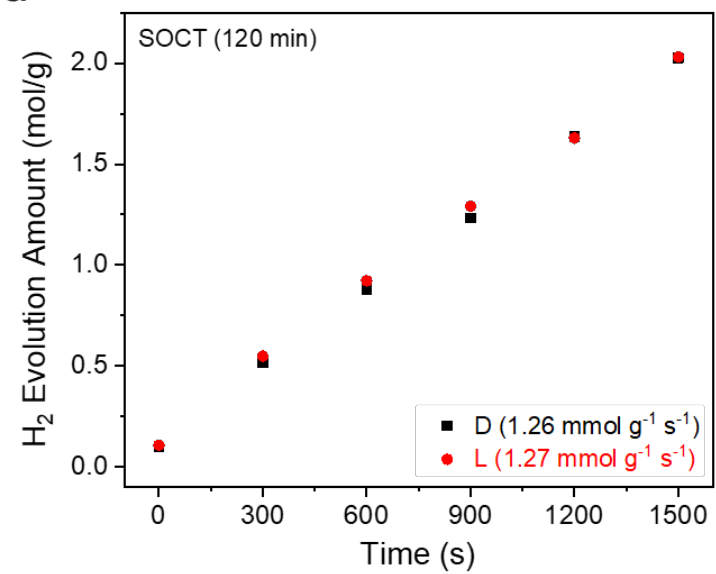

Figure S22. Time-dependent plots of $\mathrm{H}_{2}$ evolution from hydrolysis of $\mathrm{NH}_{3} \mathrm{BH}_{3}$ with with the catalysts of (a) commercial Pt, b) POCT, (c) OCT, and (d) SOCT CuPt nanocages at $27^{\circ} \mathrm{C}$ in dark (D) and under illumination of visible light (L). 